\title{
Research on Economic Irrigation Scheduling of Crops for Drip Irrigation in Greenhouse
}

\author{
Chengqi Gong ${ }^{1}$, Lishan Lin ${ }^{1}$, Yangren Wang ${ }^{1 *}, 2$, Hao Wang ${ }^{1}$, Yuan Wang ${ }^{1}$ \\ ${ }^{1}$ Department of Hydraulic Engineering, Tianjin Agricultural University, Tianjin, 300384, China \\ ${ }^{2}$ School-Enterprise Collaborative Innovation Laboratory of Water-Saving Irrigation Technology and Equipment in Tianjin, Tianjin, \\ 300384, China
}

\begin{abstract}
Aiming at the problem of water waste in the traditional greenhouse vegetable irrigation, economic irrigation schedule of three kinds of vegetables (tomato, cucumber and eggplant) were studied. The experiment was carried out in the North Country Spring Agricultural Demonstration Park in Wuqing District, Tianjin, from April 2018 to December 2018. Three vegetables were tested in 100\% (no drought) and 50\% (drought) irrigation. The water balance method was used to simulate the change of soil moisture content under greenhouse drip irrigation. The crop coefficient parameters, the temperature stress index, water stress index and dry matter conversion factor were determined using the measured data. The results show that the parameters have good applicability and can be used to describe the effects of water and temperature stress on crop growth and yield. Based on the objective of maximum economic benefit per unit area, the economic irrigation schedule of crops was determined. The analysis showed that the use of the economic irrigation schedule can save the irrigation water and increase production.
\end{abstract}

\section{Introduction}

The economic irrigation schedule is based on the maximum yield per unit area of the crop yield and the irrigation time. When optimizing the irrigation system, the irrigation quota is a fixed value, and the constraint is limited irrigation water supply. The use of greenhouse drip irrigation economic irrigation schedule can abandon the traditional management method of "much water and more manures", which can not only reduce water resources waste, reduce production costs, but also better solve the problem of excessive humidity in the greenhouse.

\section{Materials and Methods}

\subsection{Test Material}

The variety of tomato, cucumber and eggplant is "Shengmei", "Jinyun No.4", and "Anjila" respectively in this research. Two rounds of experiments were carried out in three greenhouses at the North Country Spring Agricultural Demonstration Park. The first round of test was completed from April 2018 to July 2018. During the period, cucumber, eggplant and tomato were planted on February 1, 2018 and ended on July 5, planted on February 15, 2018 and ended on July 5, planted on January 25, 2018, and ended on July 5 respectively. The second round of test was completed from July 2018 to December 2018, in which cucumber and tomato were planted on July 1, 2018 and ended on October. 12, on August 30, 2018, and December. 28 respectively. Two treatments were set up in this experiment, which were $100 \%$ irrigation (without drought) and 50\% irrigation (according to $50 \%$ irrigation of water requirement of crops, the crops would suffer drought). A representative plant was selected from each treatment, and the growth rate of stem, leaf and fruit was tested regularly. The first round of test data was used to calibrate the crop coefficient and growth model parameters, and the second round of data was used to verify the model and its applicability of parameters.

\subsection{Research Method}

\subsubsection{Determination of Economic Irrigation schedule.}

When the irrigation schedule is optimized, the given irrigating quota is $20 \mathrm{~mm}$, and the constraint is limited irrigation water supply. The pure income only includes the irrigation cost, and other expenses are regarded as constant. From this, the objective function ${ }^{[1]}$ can be written as follows (1).

$$
B=\max \left(P_{c} y-10 P_{w} M / \eta\right)
$$

Where, $B$ is the net benefit, ten thousand $¥ / \mathrm{hm}^{2} ; y$ is the fresh weight yield of crops, $\mathrm{t} / \mathrm{hm}^{2} ; M$ is the irrigating water quota, $\mathrm{mm} ; \eta$ is the irrigation water utilization coefficient, $\eta=0.9$ in this study; $P_{c}$ is the price of the crop product, $¥ / \mathrm{t}$; $P_{w}$ is the water price, $¥ / \mathrm{m}^{3}, P_{\mathrm{w}}=1.5 ¥ / \mathrm{m}^{3}$. The prices of tomato, eggplant and cucumber products 
were $4600 ¥ / \mathrm{t}, 2400 ¥ / \mathrm{t}$ and $3300 ¥ / \mathrm{t}$ respectively; 10 is the unit conversion factor.

\subsubsection{The Calculation of Crop Yield.}

In this study, the CERES crop growth model was used to calculate the cumulative dry matter weight of crops. The model described the empirical relationship between potential dry matter production $\left(P C A R D, \mathrm{~g} \cdot \mathrm{m}^{-2}\right)$ and intercepted photosynthetically active radiation (IPAR, $\left.\mathrm{MJ} \cdot \mathrm{m}^{-2} \cdot \mathrm{d}^{-1}\right)$ by crops ${ }^{[2]}$. The empirical relationship can be written as follows (2)

$$
P C A R D=7.5 \times I P A R^{0.6}
$$

The growth process of crops is often subjected to temperature stress and water stress. Under the comprehensive influence of these two environmental factors, the normal physiological mechanism of crops is inhibited, which may reduce the amount of organic matter produced by photosynthesis. Therefore, the actual dry matter production $\left(C A R B O, \mathrm{t} \cdot \mathrm{hm}^{-2}\right)$ can be written as follows (3)

$$
C A R B O=P C A R D \times P R F T \times S W D F
$$

Where, PRFT is the coefficient of temperature stress, can be calculated by formula (4); SWDF is the coefficient of water stress can be calculated by formula (5).

$$
\begin{gathered}
\text { PRFT }=\left[1-0.0025\left(T-T_{p}\right)^{2}\right]^{\sigma_{T}} \\
S W D F=\left(\frac{E T}{E T_{\mathrm{m}}}\right)^{\sigma_{\mathrm{W}}}
\end{gathered}
$$

Where, $T_{p}$ is the optimum temperature for crop growth, ${ }^{\circ} \mathrm{C} ; T$ is the average temperature of daytime, $T=0.25 T_{\min }+0.75 T_{\max } ; T_{\min }$ and $T_{\max }$ are daily minimum and maximum temperature, ${ }^{\circ} \mathrm{C} ; \sigma_{T}$ is temperature stress index, $\sigma_{W}$ is water stress index; ET is actual crop evapotranspiration, $\mathrm{mm} / \mathrm{d} ; \quad E T_{m}$ is potential evapotranspiration, $\mathrm{mm} / \mathrm{d}$.

$$
\begin{gathered}
E T=K_{\mathrm{s}} \bullet E T_{\mathrm{m}} \\
E T_{\mathrm{m}}=K_{\mathrm{c}} \bullet E T_{0} \\
K_{\mathrm{c}}=a \cdot L A I+b
\end{gathered}
$$

Where, $K_{s}$ is soil moisture correction coefficient ${ }^{[4]} ; K_{c}$ is crop coefficient; $E T_{0}$ is the reference crop evapotranspiration, $\mathrm{mm} / \mathrm{d}$; $L A I$ is leaf area index of crop; $a, b$ are factors.

The plant leaves produce organic matter through photosynthesis, and then distribute the assimilation products to the plant organs through physiological mechanism. Because the organs of the plant have different ability to produce and transport assimilation products, the organic matter produced by the leaves is not evenly distributed to all organs of the plant. The proportion of root weight to total dry matter weight is less than $4 \%{ }^{[3]}$. Therefore, the dry matter quality of the aboveground part of the crop needs to be calculated by the following formula (9).

$$
G=C A R B O \times C V F
$$

Where, $C V F$ is the dry matter conversion factor.

\subsubsection{Calibration of Model Parameters}

\section{(1) Calibration of parameters $a$ and $b$}

The parameters in the formulas can be determined according to the actual soil moisture content tested. The target minimizes sum of square difference (SSD) between the simulated soil moisture content and the measured soil moisture (formula (10)).

$$
S S D=\min \sum_{i=1}^{N}\left(\theta_{t}-\hat{\theta}_{t}\right)^{2}
$$

Where, $\theta_{t}$ and $\hat{\theta}_{t}$ are the measured and simulated average moisture content of the soil layer $0-60 \mathrm{~cm}$ respectively, $\mathrm{g} / \mathrm{g} ; i$ is the number of soil moisture test points, $N$ is the test times of soil moisture content.

$\hat{\theta}_{t}$ can be calculated by using the water balance equation of root layer (formula (11)).

$$
\hat{\theta}_{t}=\theta_{0}+\frac{M-E T}{10 \gamma H}
$$

Where, $\theta_{0}$ is soil moisture in a period, $\mathrm{g} / \mathrm{g} ; \gamma$ is soil bulk weight in the root depth $H(\mathrm{~cm}) ; M$ is irrigation water, $\mathrm{mm}$.

(2) Calibration of parameters $\sigma_{T}, \sigma_{W}$ and $C V F$

Parameter $\sigma_{\mathrm{T}}, \sigma_{\mathrm{W}}$ and CVF can be calibrated according to the measured data of crop growth rate by using equations (12) and (13).

$$
\begin{gathered}
R M S E=\left(\frac{1}{n} \sum_{i=1}^{n}\left(O B S_{i}-S M_{i}\right)^{2}\right)^{1 / 2} \\
\mathrm{RE}=\frac{\left|\mathrm{S} \mathrm{M}_{i}-O B S_{i}\right|}{O B S_{i}} \times 100 \%
\end{gathered}
$$

Where, $O B S_{i}$ is the measured value of accumulated dry weight in the upper part of the i crop; $S M_{i}$ is the simulated value of accumulated dry weight in the upper part of the $i$ crop; and $n$ is the number of tests. The smaller the standard error (RMSE) and relative error $(R E)$, the better the consistency between the simulated value and the measured value, the higher the accuracy of the model.

\section{Results and Analysis}

\subsection{Calibration Results and Analysis of Parameter $a$ and $b$}

Table1 shows the results of the crop coefficients of the three crops in the greenhouse. The results were derived from the minimum sum of squared residuals of simulated and measured soil moisture. 
Table 1. The parameters $a$ and $b$ of crop coefficient $K_{\mathrm{c}}$

\begin{tabular}{ccccccc}
\hline \multirow{3}{*}{ Parameter } & \multicolumn{3}{c}{ Initial and optimal values of three crops and their undetermined coefficients } \\
\cline { 2 - 6 } & \multicolumn{2}{c}{ Cucumber } & \multicolumn{3}{c}{ Eggplant } & \multicolumn{2}{c}{ Tomato } \\
\cline { 2 - 6 } & Initial & Optimized & Initial & Optimized & Initial & Optimized \\
\hline$a$ & 0.5 & 0.334 & 0.5 & 0.325 & 0.5 & 0.388 \\
$b$ & 0.3 & 0.009 & 0.3 & 0.002 & 0.3 & 0.007 \\
$S S D$ & & 0.00056 & & 0.00064 & & 0.00036 \\
\hline
\end{tabular}

Figure1 shows the scatter plots of simulated and measured values of soil moisture content for tomato, eggplant and cucumber. It can be seen from the figures that the simulated values of the soil moisture content were consistent with the measured values, and the correlation coefficient $R^{2}$ is above 0.96 . Therefore, it is shown that the crop coefficient parameters obtained are accurate.

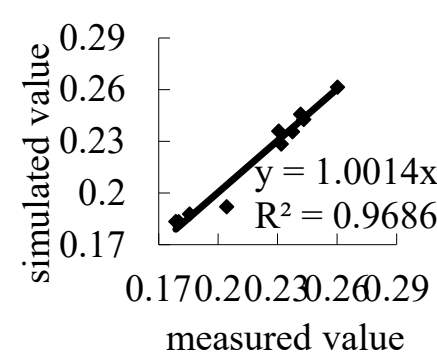

(a)

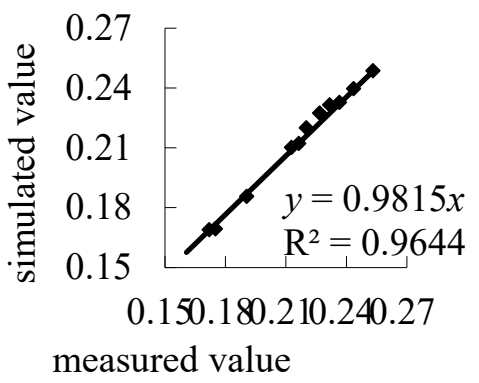

(b)

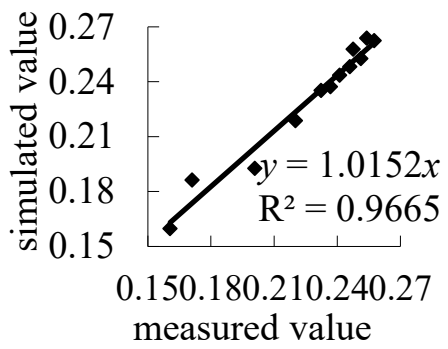

(c)

Figure 1. Scatter plot of measured and simulated soil moisture for tomato (a), eggplant (b) and cucumber (c). (2018.5.1 7.5)

\subsection{Calibration Results and Analysis of Parameter $\sigma_{\mathrm{T}}, \sigma_{\mathrm{W}}$ and CVF.}

With the data of crop growth rate tested by the first round of experiments, the three parameters $\left(\sigma_{T}, \sigma_{W}\right.$ and $\left.C V F\right)$ were calibrated. The results of calibrated parameters and statistical analysis were shown in tables 2 and 3.

Table 2. Calibration of growth model parameters for three crops.

\begin{tabular}{ccccccc}
\hline \multirow{2}{*}{ Project } & \multicolumn{2}{c}{ Tomato } & \multicolumn{2}{c}{ Eggplant } & \multicolumn{2}{c}{ Cucumber } \\
\cline { 2 - 6 } & Initial & Optimize & Initial & Optimize & Initial & Optimize \\
\hline$\sigma_{T}$ & 1.0 & 0.81 & 1.0 & 1.0 & 1.0 & 1.0 \\
$\sigma_{w}$ & 1.0 & 0.81 & 1.0 & 1.4 & 1.0 & 2.0 \\
$C V F$ & 0.60 & 0.3145 & 0.60 & 0.3018 & 0.60 & 0.2068 \\
\hline
\end{tabular}

Table 3. Statistical test of growth model parameters of three crops.

\begin{tabular}{ccccccc}
\hline \multirow{2}{*}{ Project } & \multicolumn{2}{c}{ Tomato } & \multicolumn{2}{c}{ Eggplant } & \multicolumn{2}{c}{ Cucumber } \\
\cline { 2 - 7 } & $100 \%$ water & $50 \%$ water & $100 \%$ water & $50 \%$ water & $100 \%$ water & $50 \%$ water \\
\hline$R M S E$ & 0.232 & 0.323 & 0.496 & 0.380 & 0.205 & 0.210 \\
$R E / \%$ & 3.46 & 6.83 & 1.84 & 4.06 & 2.03 & 2.02 \\
$\mathrm{R}^{2}$ (dry weight in shoot) & $0.9736^{*}$ & $0.9823^{* *}$ & $0.8696^{*}$ & $0.8851^{* *}$ & $0.8217^{*}$ & $0.8510^{* *}$ \\
$\mathrm{R}^{2}$ (dry weight of fruit) & $0.9753^{*}$ & $0.9952^{* *}$ & $0.8805^{*}$ & $0.8841^{* *}$ & $0.8606^{* *}$ & $0.8849^{* *}$ \\
\hline
\end{tabular}

*means "significant correlation"

$* *$ means extremely significant correlation.

Table 2 and table 3 showed that the simulated and measured values of dry matter weight above ground and of fruits of all crops had a high degree of fitting. The correlation coefficient $R^{2}$ was above 0.82 for dry weight of the above ground, and above 0.86 for the fruit.
According to the calibration results of the growth model parameters, the applicability is carried out by using the second round of test data. The results are shown in table 4. 
Table 4. Applicability analysis of three crop growth model parameters.

\begin{tabular}{ccccccc}
\hline \multirow{2}{*}{ Project } & \multicolumn{2}{c}{ tomato } & \multicolumn{2}{c}{ eggplant } & \multicolumn{2}{c}{ cucumber } \\
\cline { 2 - 7 } & $100 \%$ water & $50 \%$ water & $100 \%$ water & $50 \%$ water & $100 \%$ water & $50 \%$ water \\
\hline$R M S E$ & 0.721 & 0.563 & 0.202 & 0.112 & 0.324 & 0.303 \\
$R E / \%$ & 12.74 & 11.37 & 1.55 & 0.72 & 7.56 & 2.50 \\
$R^{2}$ (dry weight in shoot) & $0.8975^{* *}$ & $0.9025^{* *}$ & $0.9959^{* *}$ & $0.9811^{* *}$ & $0.9421^{* *}$ & $0.9164^{* *}$ \\
$R^{2}$ (dry weight of fruit) & $0.9853^{* *}$ & $0.9848^{* *}$ & $0.9899^{* *}$ & $0.9602^{* *}$ & $0.9472^{* *}$ & $0.9824^{* *}$ \\
\hline
\end{tabular}

*means "significant correlation"

**means extremely significant correlation.

It can be seen from table 4 that the simulated and measured values of dry matter weight aboveground and the fruit of three crops are in good agreement with each other. The correlation coefficient $R^{2}$ is above 0.91 , the $R M S E$ is less than 0.33 , the $R E$ is less than $8 \%$. The results show that the growth model parameters have good applicability.

\subsection{Optimization Results and Analysis of Economic Irrigation schedule.}

By setting several groups of different irrigation times and using the equation (1), the economic irrigation schedule is determined, and the optimal irrigation times, the corresponding crop yields and benefit of the three crops under the condition of two rounds of experimental environments are obtained, and the results are shown in Table 5.

From table 5 compared with the second round and the first round of experiment, the irrigation times of tomato, eggplant and cucumber under the economic irrigation schedule are significantly reduced, which could effectively save irrigation amount. It can be seen that crop economic irrigation schedules are different under different growing conditions, so soil moisture monitoring is needed to save water and increase yield and improve efficiency.

Table 5. Economic irrigation schedules and yield and benefit

\begin{tabular}{cccccccc}
\hline \multirow{2}{*}{ Crops } & \multirow{2}{*}{$\begin{array}{c}\text { Number } \\
\text { of rounds }\end{array}$} & $\begin{array}{c}\text { Irrigation } \\
\text { quota } / \mathrm{mm}\end{array}$ & Dry weigh & $\begin{array}{c}\text { Fresh } \\
\text { weight }\end{array}$ & $\begin{array}{c}\text { Benefit } \\
\text { /million } \\
¥ \cdot \mathrm{hm}^{-2}\end{array}$ & $\begin{array}{c}\text { ET } \\
\text { Tomm }\end{array}$ & $\begin{array}{c}\text { Irrigation time } \\
\text { (days after planting)/d }\end{array}$ \\
\hline \multirow{2}{*}{ Tomato } & First & 100 & 3.74 & 42.13 & 19.21 & 162 & $\begin{array}{c}101 / 106 / 114 / 120 / 126 \\
\text { Eggplant }\end{array}$ \\
& Second & 260 & 5.56 & 65.18 & 29.55 & 293 & $\begin{array}{c}49 / 56 / 64 / 72 / 77 / 82 / 89 / 9 \\
4 / 100 / 108 / 114\end{array}$ \\
\hline \multirow{2}{*}{ Cucumber } & First & 140 & 4.90 & 64.72 & 15.30 & 162 & $\begin{array}{c}78 / 85 / 95 / 101 / 105 / \\
110 / 118\end{array}$ \\
& Second & 140 & 5.51 & 73.03 & 17.29 & 161 & $\begin{array}{c}79 / 87 / 96 / 102 / 106 / \\
111 / 118\end{array}$ \\
\hline & First & 160 & 2.65 & 58.95 & 19.19 & 206 & $\begin{array}{c}96 / 103 / 111 / 116 / 120 / 12 \\
5 / 130 / 137\end{array}$ \\
& Second & 200 & 2.33 & 50.31 & 16.27 & 226 & $\begin{array}{c}24 / 33 / 43 / 55 / 62 / 67 / 74 / 7 \\
9 / 86 / 92\end{array}$ \\
\hline
\end{tabular}

\section{Conclusion}

(1) The results show that the model selected in this paper and the model parameters can be used to describe the effects of water and temperature stress on crop growth and yield.

(2) The economic irrigation schedule was carried out in response to the growing environment conditions in the greenhouse. The obvious effects of increasing production and income can be obtained by using the economic irrigation schedule.

\section{Acknowledgement}

Funds for this research was provided by the National Natural Science Foundation of China (51779174), and Students' Innovation and Entrepreneurship Training
Program (201810061021).

\section{References}

1. Wang, H. (2019) Study on the lower limit of economic irrigation for typical crops in greenhouse drip irrigation[D]. Tianjin Agricultural University.

2. Liu, T.M., Xie, G.S. (2010) Agricultural schedule Analysis and Simulation[M]. Science Publishing, Beijing.

3. Li, Y.X., Luo, W.H., Ni, J.H., Chen, Y.S., Xu, G.B., Jin, L., Dai, J.F., Tai, X., Han, L., Chen, C.H., Bu, C.X. (2006) Preliminary study on the model of dry matter allocation and yield prediction of greenhouse cucumber[J]. Journal of Agricultural Engineering., 02: 116-121. 
4. Wang, Y.R., Duan, X.M., Liu, P.R., Qiu, Y.M. (2014) Irrigation and drainage Engineering[M]. China Water Power Press, Beijing.

5. Kang, S.Z., Liu, X.M., Xiong, Y.Z. (1994) SoilPlant-Atmosphere Continuum Water Transport Theory and its Application[M]. Water Conservancy and Power Press, Beijing.

6. Ni, J.H. (2005) Study on Simulation Model of Tomato growth and Development in greenhouse [D]. Nanjing Agricultural University.

7. Luo, W.H., Li T.L., Chen, Q.Y., Zou, Z.R. (2008) Greenhouse crop growth Model and expert system[M]. China Agricultural Publishing, Beijing. 